\title{
Radiation Exposure Affecting Anaesthesia Personnel during Endoscopic Retrograde Cholangiopancreatography (ERCP)
}

Phawan Suton B.SN*, Phongthara Vichitvejpaisal, MD, Ph.D**, Thanaphon Thongprapan, M.D*, Warunee Boayam, B.SN*.

Department of Anesthesiology Faculty of Medicine Siriraj Hospital, Mahidol University, Bangkok 10700 THAILAND

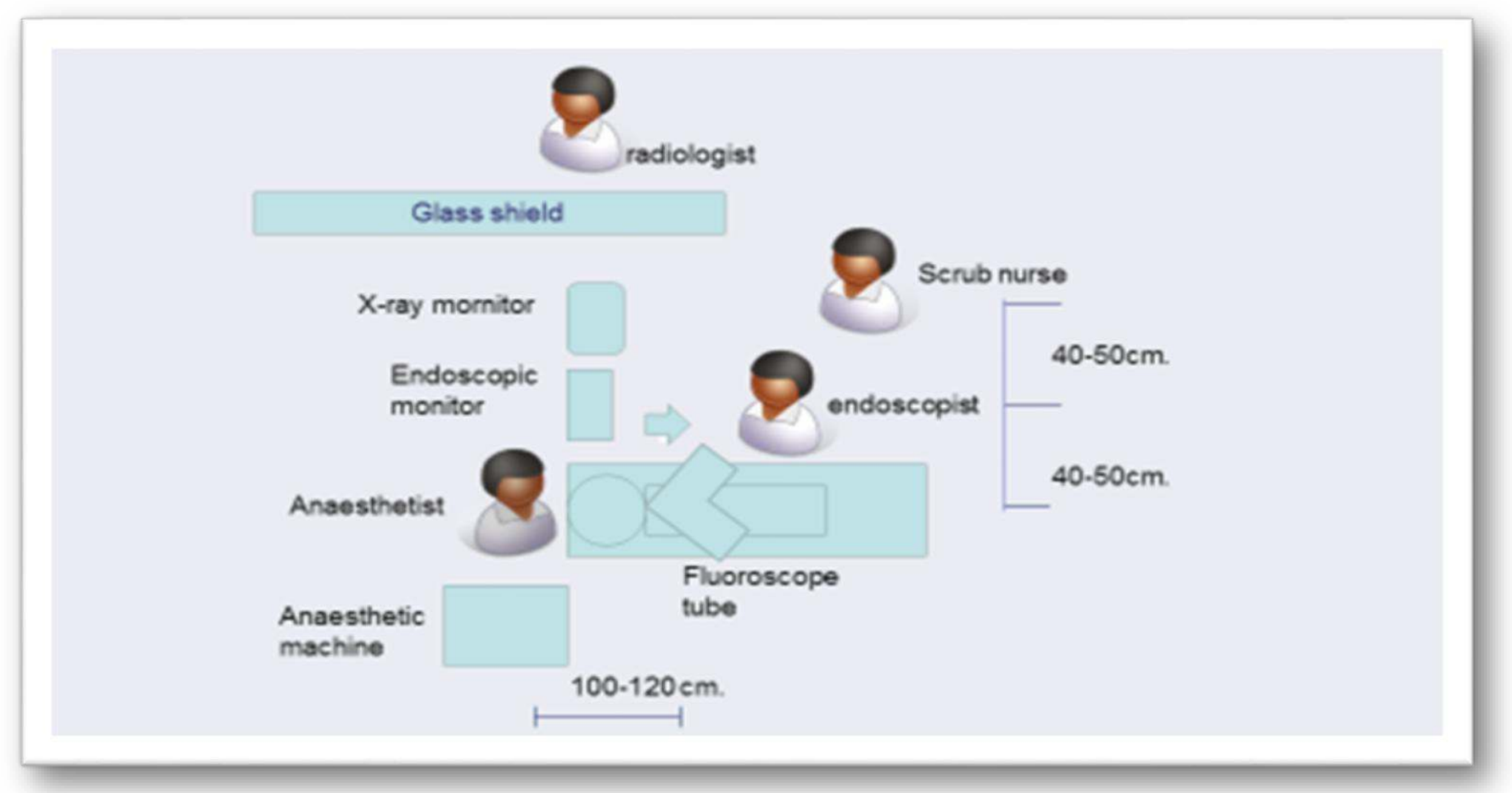

\section{Introduction}

During ERCP, anaesthetists are rinsed by radiation. The goal of study is to know the positioning of personnel relating to the distance of $\mathrm{x}$ ray source

\section{Objective}

To find out the amount of radiation affecting anaesthesia personnel

To find out the factors relating to the amount of radiation affecting anaesthesia personnel

\section{Methods}

After IRB approval, the study was registered via ClinicalTrials.gov. NCT02985164. Inclusion criteria were the 222 patients who underwent ERCP procedure.

The PDSa1 and PDSa2 were placed on the outside and inside of a lead shirt respectively. The shirt-covered box was close to an anaesthetic machine $(96.5 \mathrm{~cm}$ from the tube).

The PDSb1 and PDSb2 were placed on the outside and inside of the glass shield (204 cm from the tube) of control room.

Both position A and B were $160 \mathrm{~cm}$. above the floor.

Data were expressed as mean and standard deviation. Categorical data were compared by using Chi-square test; while, the recorded data using dependent t-test. A $\mathrm{p}<0.05$ was considered statistically significant difference at $95 \%$ confidence interval.

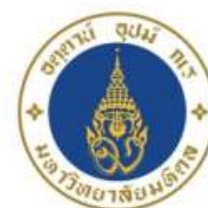

$$
\begin{aligned}
& \text { Mahidol University } \\
& \text { Wisdom of the Land }
\end{aligned}
$$

\section{Result}

The amount of radiation recorded on the outside of the lead shirtcovered box and the glass shield was higher significantly than that of the inside. Though, the outer parts of these two locations exposed to the ray differently; it was not statistically significant (Table 1).

Moreover, the shirt apron and the glass shield were effective to block the ray emission $96.22 \%$ and $95.46 \%$ respectively.

Table 1 The amount of radiation at the outside and inside of the shirt-covered box and the glass shield.

\begin{tabular}{|l|c|c|c|c|}
\hline & $\begin{array}{c}\text { Outside } \\
\left(10^{-3} \mathrm{mSv}\right)\end{array}$ & $\begin{array}{c}\text { Inside } \\
\left(10^{-3} \mathrm{mSv}\right)\end{array}$ & $\begin{array}{c}\% \\
\text { difference }\end{array}$ & P \\
\hline $\begin{array}{l}\text { Shirt- } \\
\text { covered } \\
\text { box }\end{array}$ & $5.3 \pm 7.9$ & $0.2 \pm 0.6$ & 96.2 & $0.000^{*}$ \\
$\begin{array}{l}\text { Lead glass } \\
\text { shield }\end{array}$ & $4.4 \pm 5.9$ & $0.2 \pm 0.7$ & 95.5 & $0.000^{*}$ \\
\hline \multicolumn{2}{|c|}{ Discussion } \\
\hline
\end{tabular}

The current study revealed that the amount of radiation recorded on the outside of the shirt-covered box and the glass shield was higher significantly than that of the inside.

The shirt apron and the glass shield were effective to block the ray emission. These findings were higher than that found by Hyun SJ, et al. (2016) who studied in adult patients with degenerative lumbar disorders, scheduled to undergo posterior lumbar interbody fusion. They claimed that the radiation blocked by the aprons was $37.1 \%$.

Therefore, an ERCP operating theatre was a place of radiation risk. The effective protection devices were highly recommended for all personnel with distance during the procedure

\section{Conclusion}

The amount of radiation affected anaesthesia personnel was approximately $5 \%$. Distance appeared tobe the key factor for its hazard. 